\title{
Comparison of Electric and Gas Turbine Drive Types at Pump Stations
}

\author{
Vitaly Shpilevoy ${ }^{1}$, Anton Zakirzakov ${ }^{1, *}$ and Alexander Shabarov ${ }^{2}$ \\ ${ }^{1}$ Industrial University of Tyumen, 625001 Volodarskogo str. 38, Tyumen, Russia \\ ${ }^{2}$ Tyumen State University, 625001 Volodarskogo st. 6, Tyumen, Russia
}

\begin{abstract}
The article analyzes the state of an extensive network of main oil pipelines in Tyumen region on the basis of statistical data, as well as the ways for the efficiency improving of energy-saving policy for the main oil transportation are suggested.
\end{abstract}

\section{Introduction}

Issues related to the energy consumption saving are more and more likely to be at the center of the worldwide society attention. The urgency of energy saving [6] focus caused by the limited and slow recovery pace of natural energy sources. It should be noted that the main oil transportation is one of the largest consumers of fuel and energy resources in the Russian Federation [3, 4, 18, 24].

The existing system of oil and gas pipelines in Russian Federation has developed in 6080 years of the last century, and the greatest development of their structures was caused by the necessity of large volumes of oil and gas transportation from Western Siberia fields to the central regions of the country as well as for export [20,22].

The state development policy of Russian export main oil pipelines determined the necessity of the creation of two new directions: [13]

- the Northern one: oil export by sea to the countries of North-West Europe and Northern

America from Western Siberia fields (the beginning in the Surgut area) as well as

Timan-Pechersk oil and gas province to the Barents Sea coast and further;

- the Eastern one: with the prospects of the resources development of Eastern Siberia and

Far East, as well as the oil export organization to China, Japan and other countries of the

Asian-Pacific region.

Since a significant routes portion of both projects is planned for the northern latitudes, as well as for Siberia area, there is the design and construction experience of such oil pipeline systems under the appropriate climatic conditions in Russia and it can be complemented by the foreign one in some aspects $[9,10]$.

Main pump units are powerful energy consumers, so their efficient and economical operation is a very important task of operating organizations.

\footnotetext{
* Corresponding author: zakir1404@mail.ru
} 
Energy consumption for oil transportation can be reduced by choosing the optimal energy drive type of the pump stations as at construction, and at reconstruction of the existing oil pipeline routes, because the main electrical pump drive has no alternative already at the drawing up stage of regulatory and technical documentation $[11,12]$.

Electricity is the main share of energy in the oil pipeline transportation (Figure 1) [21]. GOST for oil pump units, developed in the USSR, only provided the electrical drive for the main pumps, which was caused by the progressive policies of the world powers in the field of the development of a unified power supply system. The standard technical documentation of Russian oil transportation companies took the place of the Soviet GOSTs. It also leaves no choice for a design engineer relative to the main drive units.[15]

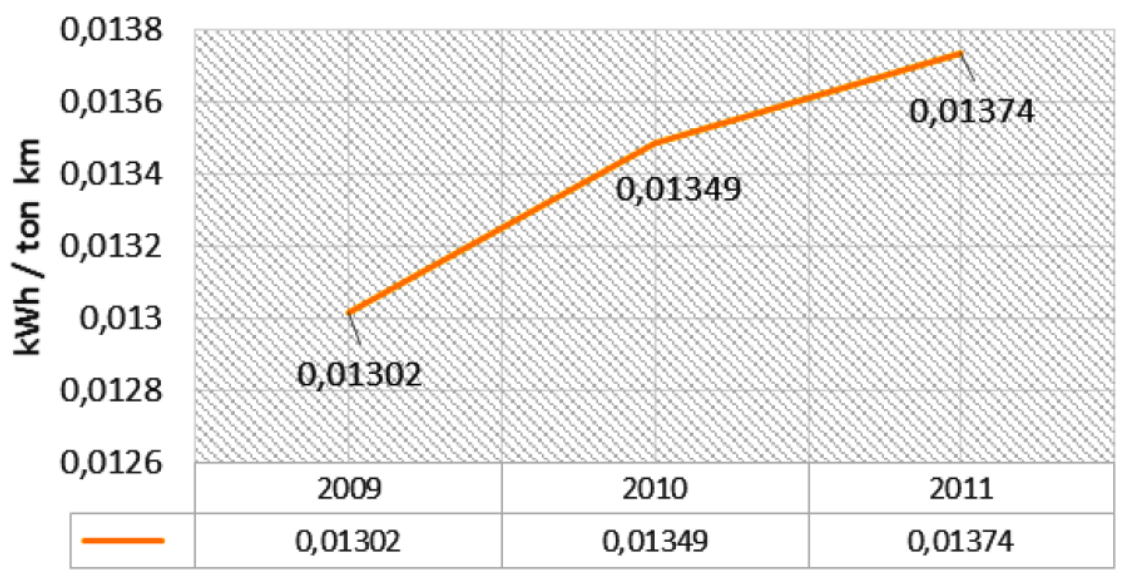

Fig. 1. Specific electricity consumption for oil pipeline transportation in Tyumen region.

\section{Comparison of Electric and Gas Turbine Drive Types at Pump Stations}

One of the conditions for the dynamic development of the main oil transportation is the pumping cost reducing, which important component the power resources cost is [26]. There are various ways to reduce the energy consumption [25]:

- optimization of oil pumping modes applying the modern methods of pipeline productivity control;

- reduction of energy losses for operating equipment, power transmission lines, distribution networks;

- introduction of modern methods for reducing the pipeline hydraulic resistance;

- the technique optimization for a drive pump units choice because the main pump electrical drive has no alternative already at the drawing up stage of regulatory and technical documentation.

With the development the system of gas supply the oil pump units with gas turbine drive can compete with the existing ones [1]. It is especially important to use them in areas where there is no unified system of power supply. The drive type choice of oil pump system is affected by a number of fundamental factors. First of all there is the availability of powerful energy sources, as well as technical, energy and economic aspects.[14]

In the initial period of the national development of oil pipeline transport a choice of the pump units drive type for the oil pump stations was not difficult. In many cases, there was only one energy source - the combustion energy of the product being pumped. This provided the autonomous reliable and uninterrupted energy supply [5]. This solution is 
widely used at present for a gas turbine drive in the compressor stations of main gas pipelines, where the energy source is the combustion energy of the pumped gas, and automatic control and regulation system ensures perfect all the requirements for the main gas pipelines operation. [17, 19]

Many years of research and practice of energy drives use at the compressor stations of domestic main gas pipelines determined the preferred appliance of gas turbine units of various capacities and types. It is rational to use them at the pumping stations, located in remote areas from the centralized electricity supply under difficult climatic conditions. It is efficient to use the electrically driven pump stations in areas with large electric power systems with relatively cheap electricity of nuclear and hydro power plants.

For many years, the argument for energy autonomy outweighed the arguments in favor of appliance of other drive types. However, the electrical drive has been widely used in the following and in remote areas as well as areas with complicated environmental climatic and geographical conditions (Western Siberia), for oil pump stations of main oil pipelines. The domestic ideological motivation of priority and the statement that "the electrification is the key element of economic development of the socialist society" has greatly contributed to this. [13]

In addition to this, the planning of the use of each type pumps drive at oil pump stations should be determined by the presence of an energy source and economic aspects of its expediency and necessity connected with the unification of the equipment, different for each energy source (electricity, oil, gas). The influence of factors determining the decision making about a drive type may have a different weight in each case. It is necessary to carry out technical and economic comparisons.

From the energy point of view the products useful factor (KPI) of the drive energy is defined as the product of the efficiency factors of the electric power circuit elements:

$$
\eta_{E}=E_{l}^{i}=\eta_{P} \cdot \eta_{I S} \cdot \eta_{D S} \cdot \eta_{L} \cdot \eta_{n} \cdot \eta_{E D},
$$

where $\quad \eta \mathrm{P}$ - efficiency factor of supplying power plant (for thermal power plants 0.35-0.4, for nuclear and hydro power plants it is significantly higher);

$\eta \mathrm{IS}$ and $\eta \mathrm{DS}$ - efficiency factor of raising and lowering substation (0.98);

$\eta \mathrm{L}$ - efficiency factor of electric power line (0.95);

$\eta n-$ efficiency factor of the distribution (power) network (0.96);

$\eta E D$ - efficiency factor of the drive electric motor (0.85-0.9).

At heat power plants $\eta \mathrm{E}=0.27-0.31$.

The modern gas turbine motor with a gas turbine drive has an efficiency factor of 0.25 0.29 (in the future it will rise up to $0.35-0.4$ ). In addition it has the efficiency use factor of a gas turbine drive $\eta \mathrm{GTD}$.

In the energy aspect the electric drive of the heat power plants and the gas turbine drive of the oil pump stations are almost equally effective.

From the economic point of view the efficiency calculation of the compared oil pumping systems is fairly routine $[15,16]$, requiring the synthesis and evaluation of a large number of input data in the current conditions, the previous design decisions, the future operation conditions of the oil pipeline and foreign experience.

Lower costs for buildings and equipment are greatly increased due to the costs for construction of the power supply system when uncontrolled pumps electrical drive. Composition and costs of related equipment (installations for selection, preparation and use of fuel) increase significantly when the pumps gas turbine drive $[7,8]$.

The estimated prime cost of electric power used at the industrial enterprises of the gas industry, can be made according to the specific fuel consumption spent for $1 \mathrm{kWh}$ energy generation. 
Indeed, if the average efficiency factor of heat power plants operating on gas would be taken at the level of $32 \%$, so the specific fuel equivalent consumption for generation of 1 $\mathrm{kWh}$ of energy (combustion heat of $1 \mathrm{~kg}$ fuel equivalent is taken equal to $29.3 \mathrm{MW} / \mathrm{kg}$ ) would be equal to $\mathrm{kg} /(\mathrm{kWh})$ :

$$
B_{s \cdot f}=0,123 / 0,32=0,384
$$

Expressed in terms of natural gas where the fuel combustion heat is taken as $49 \mathrm{MJ} / \mathrm{kg}$, and the gas density under standard conditions $-\rho S T=0.6-1.205=0.72 \mathrm{~kg} / \mathrm{m}$, the average specific fuel consumption (of natural gas), released for a $1 \mathrm{~kW} * \mathrm{~h}$ is equal to:

$$
b_{n g}=0,384-29,3 / 49-0,23 \mathrm{~kg} /(\mathrm{kWt}-\mathrm{h}) \text { or } 0,319 \mathrm{~m}^{3} /(\mathrm{kWt}-\mathrm{h})
$$

Knowing the numerical value of the gas selling price $(\mathrm{P}, \mathrm{Rub} / \mathrm{kg})$, it is easy to determine the cost of $1 \mathrm{kWh}$ of electric energy at the power station running on gaseous fuel.

The component of the fuel cost at heat power plants in the total electric power cost is usually at the level of $60-65 \%$.

The rest is accounted for by labor and material costs $(\sim 12-15 \%)$, investments $(\sim 5-$ $7 \%)$, taxes $(\sim 5 \%)$, profit $(\sim 15 \%)$, etc.

Thus, the ratio of presented efficiency factors of the gas turbine and electric motor on the pump coupling on the one hand, and the prices relation of the energy carriers in the rapid calculation on the other hand can determine the rational use areas for each drive type (Figure 2).

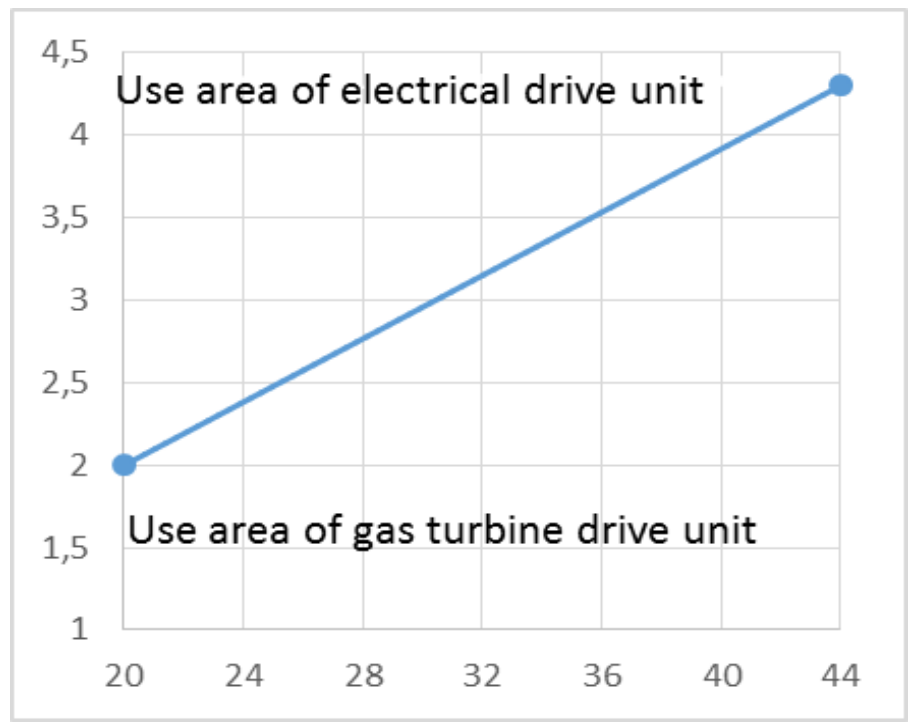

Fig. 2. Rational use areas of gas turbine and electrical drive units.

It is shown that the cost of one kWh of energy from the gas turbine units is about $2.5-3$ times lower than from the electrical driven ones at current prices for electricity and fuel gas.

The gas turbine drive in the drive of main oil pipelines pumps can be used in areas with different climate conditions. It is preferable to use them in areas with relatively low mean average temperature of the ambient air, that is, in the Far North's and Siberia's areas.

In the world practice there are enough examples of the widespread use of gas turbine drives at the main oil pipelines, including the Trans-Alaska one extending for about 1,300 $\mathrm{km}$ under northern conditions close to the Western Siberia's and the Russian Far North's ones. 
The question of pumped fuel use takes a special place in the operation of gas turbine drive on the oil pipelines. Such fuel types, as kerosene, gasoline, diesel, natural and associated gas, meet directly the requirements to the gas turbine fuel. Natural gas is effective used when the gas pipeline is laid parallel to the oil one [27]. The associated gas can be used, if it is pumped together with oil. Pumped crude oil can be used after the preparation at special block rectification units. After rectification of the oil $25-30 \%$ of natural gas liquids (NGLs) are obtained, and the residue (heavy fuel oil) is pumped into the oil pipeline. Application of such systems is economically advantageous in areas remote from the powerful electric energy supplies. Combustion products disposal solves the problem of heat consumption at oil pumping stations.[17]

The gas turbine drive is the most economical and controlled electrical drive system - the least economical for controlling of the pump unit supply.

There are also isolated examples of evaluation and use of the regulated electrical and gas turbine drive in domestic application area of drive pump units on main oil pipelines.

Developments of OAO "Aviadvigatel" for the "Sakhalin-2" project are of particularly attention [2].

However, further conducting of technical and economic evaluation taking into account the reliability for the specific operating conditions is necessary to fully evaluate the effectiveness of a particular type of oil pump station drive. In areas with a low cost of electricity from nuclear or hydro power plants the electrical drive at oil pump station may be more economical than the gas turbine drive. At the same time the gas turbine drive at the oil pump station may be preferred under conditions of frequent changes in the oil pipeline operation mode.

\section{Conclusion}

The examples given above show, that the electrical drive is not uncontested drive in oil pipeline transportation systems. There is a need to establish technique of a choice of the pump unit drive, which allows comparing such factors as distance from the power supply sources, the pumped oil composition, the presence of a developed gas supply system, etc.[18]

The implementation of the mentioned measures may be the key factor for significant increase in the efficiency of energy-saving policy on the main oil transportation as well as providing the electric power saving and increase the reliability of the main oil pipelines system.

\section{References}

1. V. Durymanov, A. Ivanov, K. Ishbulatova, A. Stepanov, M. Surnikov, Turbines and diesel engines, 3, (2013)

2. A. Inozemtsev, F. Khairullin, Energy and transport of gas, 17, (2010)

3. The use of fuel and energy resources in Tyumen region in 2009-2012, Statistical Bulletins

4. The comprehensive program "Energy saving and the energy efficiency enhance in Tyumen region" for 2010-2020

5. A. Smirnov, A. Vengerov, S. Dudin, Yu. Zemenkov, Oil and gas, 3, 74-77 (2010)

6. I. Tyrylgin, V. Shpilevoy, Yu. Zemenkov, Oil and gas, 6, 73-81 (2012)

7. V. Shpilevoy, I. Tyrylgin, Yu. Zemenkov, Oil and gas, 5, 75-78 (2012)

8. A. Kulikov, V. Petryakov, I. Seroshtanov, Business Magazine Neftegaz.RU, 11-12, 36$40(2015)$ 
9. A. Kulikov, New technologies - oil and gas region: Proceedings of the scientificpractical conference of students, graduate students and young scientists, 102-105 (2010)

10. A. Kulikov, E. Komarova, Problems of functioning of transport: Proceedings of the International scientific-practical conference, 188-189 (2010)

11. V. Nekrasov, R. Levitin, Fundamental and applied research: Problems and results, 13, 223-228 (2014)

12. V. Nekrasov, R. Levitin, I. Tirilgin, Yu. Zemenkov, A device for improving the performance properties of vertical steel tanks. Pat. № 2012125478/05 (RU), declared 10.12.13 (2013)

13. V. Kurushina, Yu. Zemenkov, WIT Transactions on Ecology and the Environment, 190, 2, 881-888 (2014)

14. V. Antip'ev, A. Nevolin, Yu. Zemenkov, Neftyanoe Khozyaistvo - Oil Industry, 10, 46-48 (1981)

15. Yu. Zemenkov, V. Shalay, M. Zemenkova, Procedia Engineering, 113, 254-258 (2015)

16. Yu. Zemenkov, V. Shalay, M. Zemenkova, Procedia Engineering, 113, 312-315 (2015)

17. A. Pimnev, Thesis of Candidate of Technical Sciences, 169 (2006)

18. E. Kurushina, V. Kurushina, Life Science Journal, 11(11), 517-521 (2014)

19. A. Antropova, A. Zakirzakov, Oil and gas in Western Siberia: Proceedings of the International scientific conference, 64-66 (2013)

20. A. Zakirzakov A. Egorov, Modern problems of science and education, 1-1, 309 (2015)

21. Yu. Zemenkov, V. Shpilevoy, S. Podorozhnikov, A. Zakirzakov, Energotechnological complexes at the design and operation of transport and storage facilities of hydrocarbons (TSOGU, Tyumen, 2014)

22. Yu. Zemenkov, V. Kurushina, Mining informational and analytical bulletin (scientific and technical journal), 3, 85-98 (2013)

23. M. Zemenkova, I. Seroshtanov, V. Kurushina, S. Toropov, Yu. Zemenkov, Territory Neftegaz, 10, 80-86 (2013).

24. Yu. Zemenkov, V. Kurushina, A. Vylegzhanina, V. Barmenkova, N. Khairullina, Modern management and innovation, science and technology policy (Publishing House Science and Innovation Center, Ltd., St. Louis, 2013)

25. A. Gumerov, R. Gumerov, A. Akberdin, Operation of equipment pumping stations (Nedra-Business Center, Ltd, Moscow, 2001)

26. L. Paleeva, A. Zakirzakov, Oil and Gas Terminal: Proceedings of the International scientific conference, 182-184 (2015)

27. I. Kiryanov, S. Toropov, V. Toropov, Neftyanoe Khozyaystvo - Oil Industry, 8, 48 (2015) 